\title{
Utility of Squaraine Dyes for Dye-Sensitized Photocatalysis on Water or Carbon Dioxide Reduction
}

Minji Jo, Sunghan Choi, Ju Hyoung Jo, So-Yoen Kim, Pil Soo Kim, Chul Hoon Kim, Ho-Jin Son,* Chyongjin Pac, and Sang Ook Kang*

Department of Advanced Materials Chemistry, Korea University, Sejong 30019, Korea.

\begin{tabular}{|c|c|c|}
\hline \multicolumn{3}{|c|}{ Table of contents } \\
\hline Sections & Titles & pages \\
\hline \multicolumn{2}{|c|}{ General procedures } & S2 \\
\hline Scheme S1 & Synthetic routes of the SQ antenna & S3 \\
\hline Figure S1 & IR spectra of bare $\mathrm{TiO}_{2}$ and $\mathrm{TiO}_{2} / \mathrm{Re}(\mathrm{I})$ particles & S4 \\
\hline Figure S2 & $\begin{array}{l}\text { Time-resolved fluorescence signals of squaraine dyes in DMF and SQ-fixed TiO2 } \\
\text { mesoporous film on optical window. Detection wavelength was } 680 \mathrm{~nm} \text {. }\end{array}$ & S5 \\
\hline Figure S3 & ${ }^{13} \mathrm{C}$ isotope tracer experiment for $\mathbf{S Q}_{\mathbf{C A}} / \mathrm{TiO}_{2} / \mathrm{Re}(\mathrm{I})$ performed by GC-Mass & S6 \\
\hline Figure S4 & $\begin{array}{l}\text { Diffuse-reflectance spectra (DRS) comparison of } \mathbf{S Q} / \mathrm{TiO}_{2} / \mathrm{Pt} \text { powders after } \\
\text { photoreaction }(0 \text { and } 5 \mathrm{~h})\end{array}$ & S7 \\
\hline Figure S5 & ${ }^{1} \mathrm{H}$ NMR spectroscopic view of $\mathbf{S} \mathbf{Q}_{\mathrm{CA}}$ & S8 \\
\hline Figure S6 & ESI-Mass spectra of $\mathbf{S} \mathbf{Q}_{\mathbf{C A}}$ & S9 \\
\hline Figure S7 & ${ }^{1} \mathrm{H}$ NMR spectroscopic view of $\mathbf{S} \mathbf{Q}_{\mathbf{P A}}$ & S10 \\
\hline Figure S8 & ESI-Mass spectra of $\mathbf{S Q}_{\mathbf{P A}}$ & S11 \\
\hline Figure S9 & Cyclic voltammograms of the $\mathbf{S Q}_{\mathbf{C A}}$ and $\mathbf{S} \mathbf{Q}_{\mathbf{P E}}$ & S12 \\
\hline Figure S10 & $\begin{array}{l}\text { Plots of } \mathrm{H}_{2} \text { formation }(\mu \mathrm{mol}) \text { versus time for } \mathbf{S Q} / \mathrm{TiO}_{2} / \mathrm{Pt} \text { with the variation of } \mathbf{S Q}_{\mathbf{C A}} \text { and } \\
\mathbf{S Q}_{\mathbf{P A}} \text { loading amount from } 0.2 \text { to } 4.8 \mu \mathrm{mol}\end{array}$ & S13 \\
\hline Figure S11 & $\begin{array}{l}\text { Time courses of } \mathrm{H}_{2} \text { production by irradiation at }>500 \mathrm{~nm} \text { for } \mathbf{S Q}_{\mathbf{C A}} / \mathrm{TiO}_{2} / \mathrm{Pt} \text { and } \\
\mathbf{S Q}_{\mathbf{P A}} / \mathrm{TiO}_{2} / \mathrm{Pt}\end{array}$ & S14 \\
\hline \multirow[t]{2}{*}{ Figure S12 } & $\begin{array}{l}\text { Plots of } \mathrm{CO} \text { formation versus time for } \mathbf{S Q}_{\mathbf{C A}} / \mathrm{TiO}_{2} / \mathrm{Re}(\mathrm{I}) \text { under irradiation at } \lambda>400 \mathrm{~nm} \text { and } \\
\text { at } \lambda>500 \mathrm{~nm}\end{array}$ & S15 \\
\hline & DFT calculation method & S16 \\
\hline Figure S13 & Spatial distributions for the frontier orbitals and calculated energy levels of $\mathbf{S} \mathbf{Q}_{\mathbf{C A}}$ & S17 \\
\hline Figure S14 & Spatial distributions for the frontier orbitals and calculated energy levels of $\mathbf{S} \mathbf{Q}_{\mathbf{P A}}$ & S18 \\
\hline Figure S15 & Spatial distributions for the frontier orbitals and calculated energy levels of SQ1 & S19 \\
\hline Table S1 & Multi-exponential fitting results of time-resolved fluorescence signals. & S20 \\
\hline \multicolumn{2}{|l|}{ References } & S21 \\
\hline
\end{tabular}


General procedures: All reagents were purchased from Aldrich and used without further purification. All manipulations were performed under a dry nitrogen or argon atmosphere by using standard Schlenk techniques. $N, N$-Dimethylformamide (DMF) was distilled from calcium hydride and stored over molecular sieves. Dichloromethane was refluxed over and distilled from phosphorus pentoxide $\left(\mathrm{P}_{2} \mathrm{O}_{5}\right)$ before use. The ${ }^{1} \mathrm{H}$ and ${ }^{13} \mathrm{C}$ NMR spectra were recorded on a Varian Mercury 300 spectrometer (operating at 300.1 and $75.4 \mathrm{MHz}$ ) and Bruker Ascend 400 spectrometer in KBSI Ochang Center (operating at $400.1 \mathrm{MHz}$ and $100.6 \mathrm{MHz}$ ), respectively. The absorption and photoluminescence spectra were recorded on an Agilent Technologies, Cary 5000 UV/Vis/NIR scanning spectrophotometer and on a VARIAN Cary Eclipse fluorescence spectrophotometer, respectively. The diffuse reflectance UV-visible absorption spectra of powder samples were recorded on a Scinco spectrophotometer S-3100. The IR spectra were taken on the Nicolet 6700 FTIR spectrometer (from Thermo Electron Corporation). The cyclic voltammetry (CV) experiments were carried out in distilled, degassed THF containing $1 \mathrm{mM} \mathrm{SQ}$ and $0.1 \mathrm{M}$ tetrabutylammonium hexafluorophosphate $\left(\mathrm{TBAPF}_{6}\right)$ at room temperature using an electrochemical analyser (CH Instruments, CHI660e). A platinum disk (dia. $1.6 \mathrm{~mm}$ ), platinum wire, $\mathrm{Ag} / \mathrm{AgNO}_{3}(0.1 \mathrm{M})$, and ferrocene/ferrocenium were used as the working, counter, reference electrodes, and an internal potential marker, respectively. All potentials measured vs. ferrocene/ferrocenium $\left(\mathrm{Fc} \mid \mathrm{Fc}^{+}\right)$couple were converted to the saturated calomel electrode (SCE) by addition of $+0.38 \mathrm{~V}$. All gaseous and liquid products produced from photoreaction were analyzed by gas chromatography (GC) and Waters high-performance liquid chromatography (HPLC) equipped with Rspak KC-811 column, respectively. GC-Mass spectra for ${ }^{13} \mathrm{C}$ isotope experiment was measured by Agilent Technologies 7890A GC equipped with 5975C inert MSD with TripleAxis detector using a SUPELCO Carboxen ${ }^{\mathrm{TM}} 1010$ PLOT Fused Silica Capillary column. 


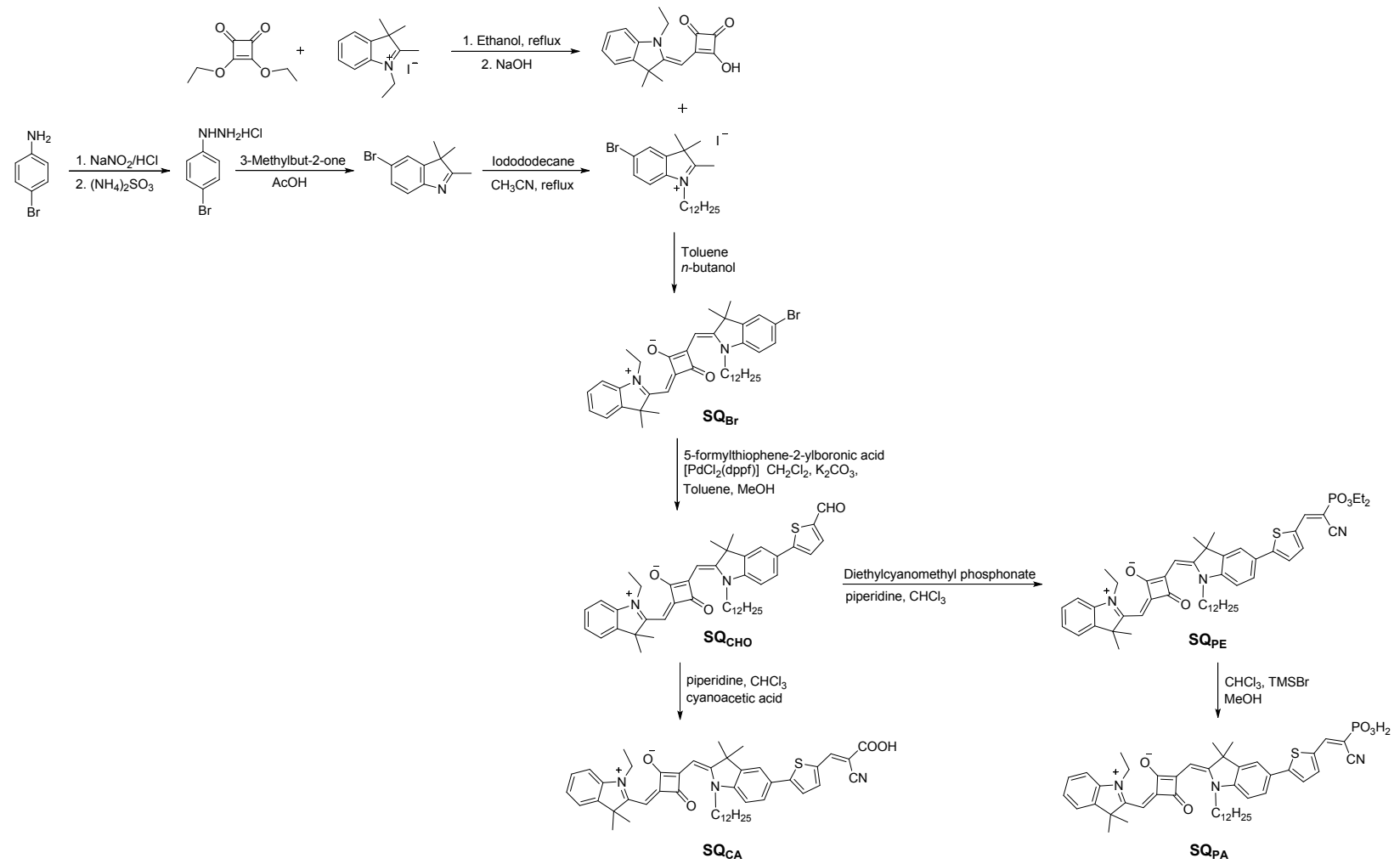

Scheme S1. Synthesis of the squaraine dye molecules (SQ $\mathbf{C A}, \mathbf{S} \mathbf{Q}_{\mathbf{P E}}$, and $\left.\mathbf{S Q}_{\mathbf{P A}}\right)$. 


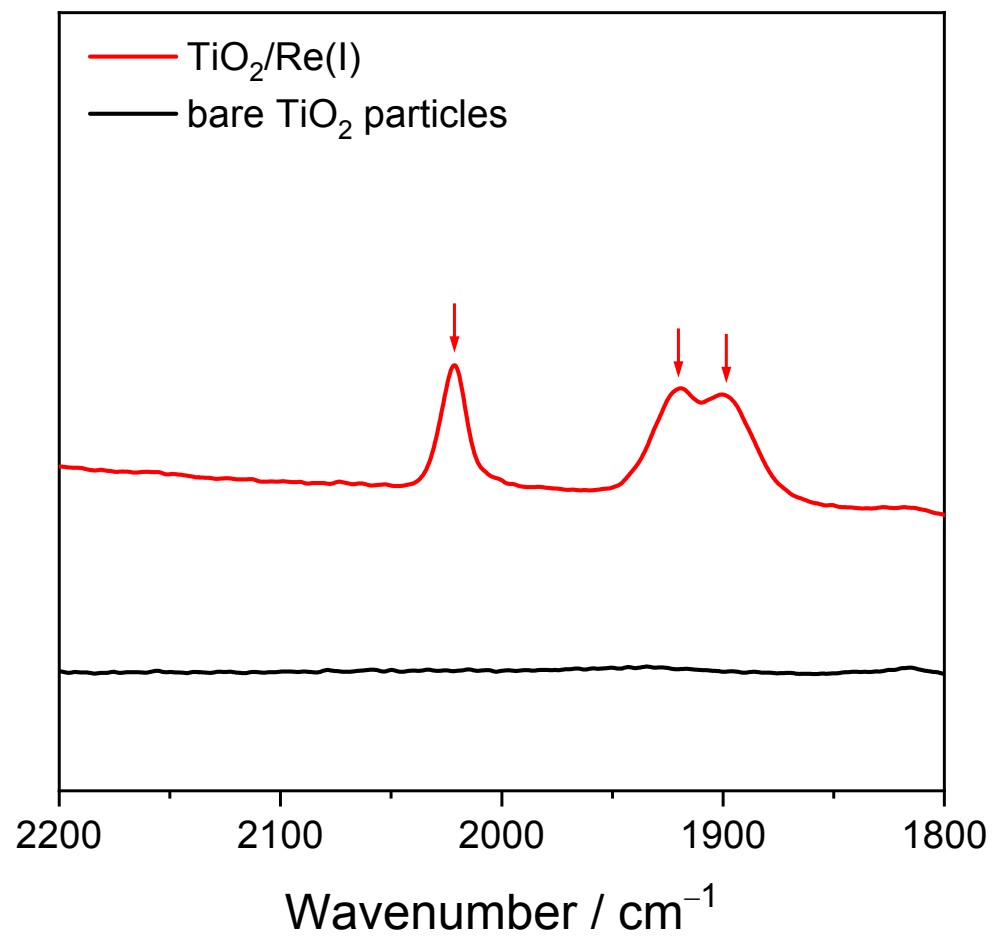

Figure S1. IR spectra of bare $\mathrm{TiO}_{2}$ (black line) and $\mathrm{TiO}_{2} / \mathrm{Re}(\mathrm{I})$ (red line) particles in $\mathrm{KBr}$ disks (sample: $\mathrm{KBr} \approx 1: 100$ ). Red arrows indicate the absorptions of the CO ligands of $\operatorname{Re}(\mathrm{I})$ catalyst anchored. 


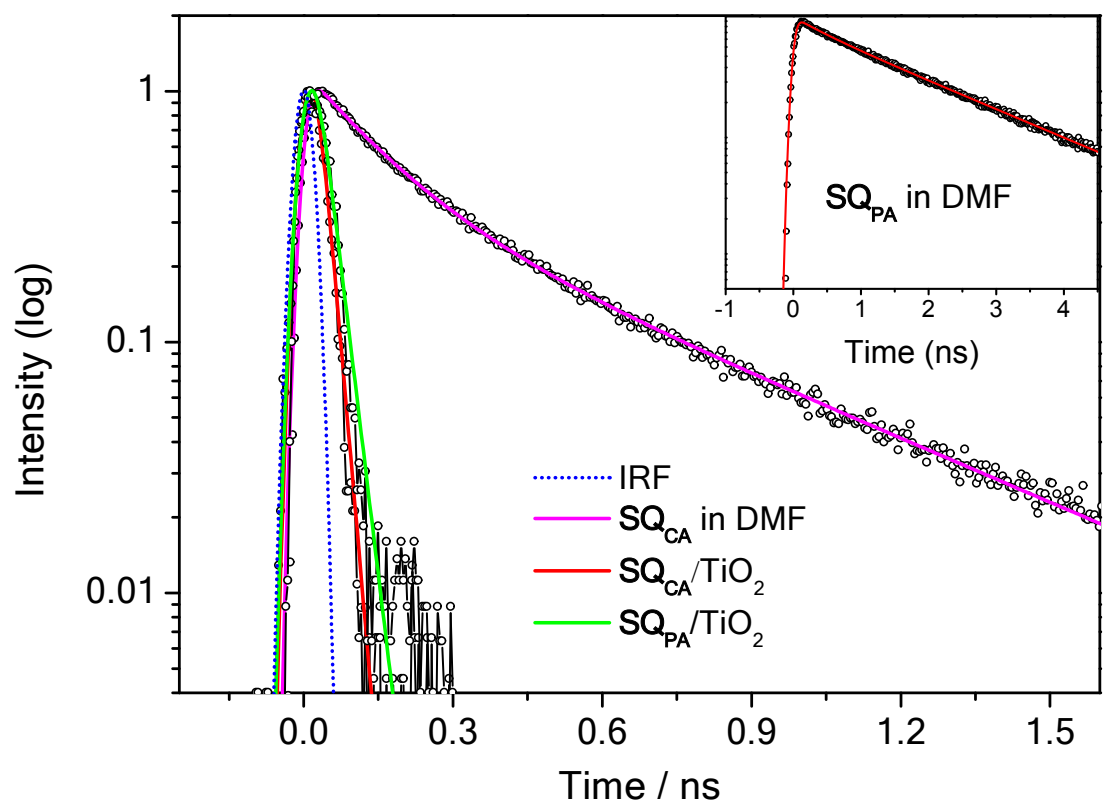

Figure S2. Time-resolved fluorescence signals of squaraine dyes in DMF and SQ-fixed $\mathrm{TiO}_{2}$ mesoporous film on optical window. Detection wavelength was $680 \mathrm{~nm}$. 


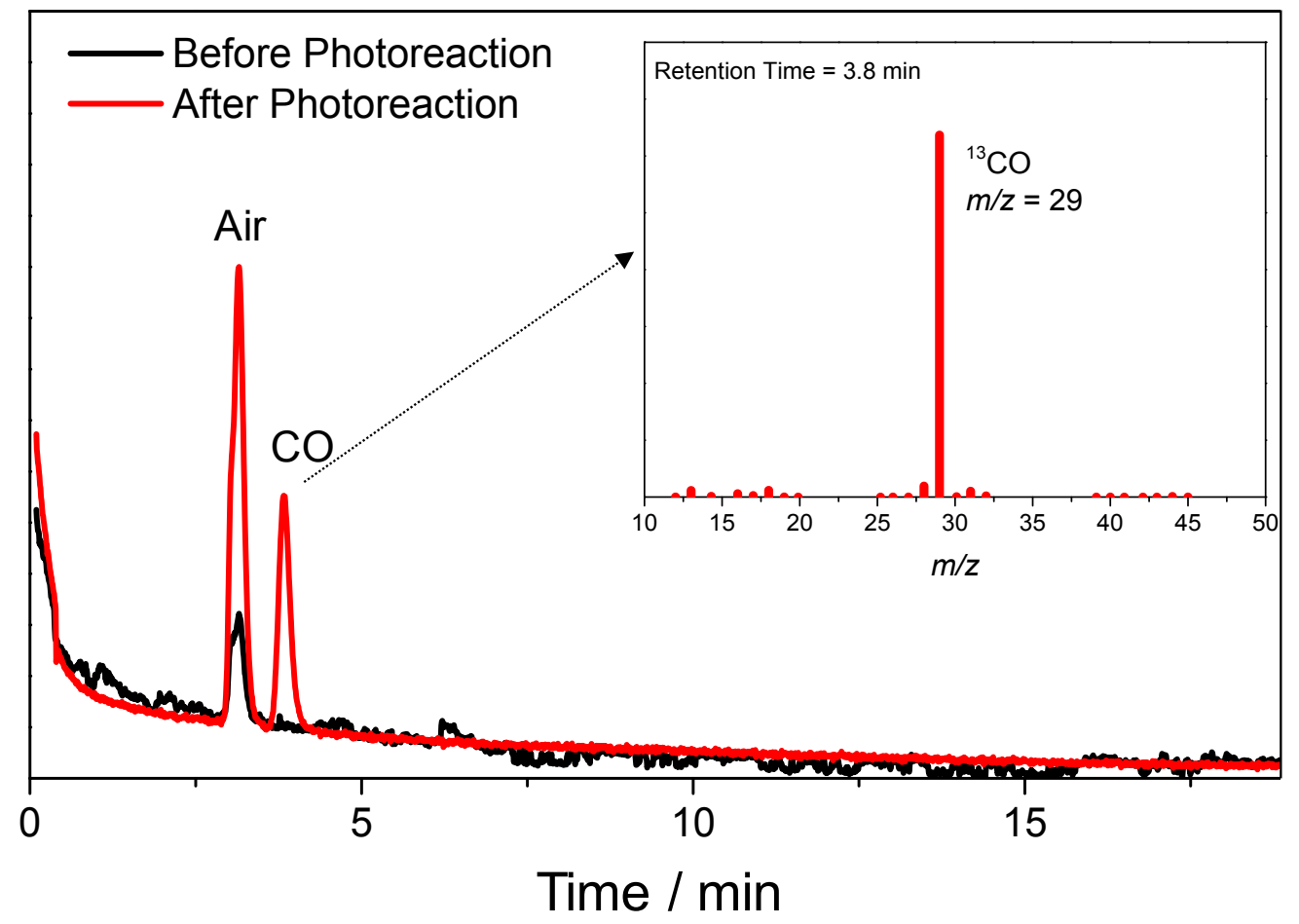

Figure S3. GC spectrum of gas in the reaction vessel before photoreaction (black line) and after irradiation (red line). Inset describes the MS spectra of CO peak at $t_{\mathrm{R}}=3.8 \mathrm{~min}$. 

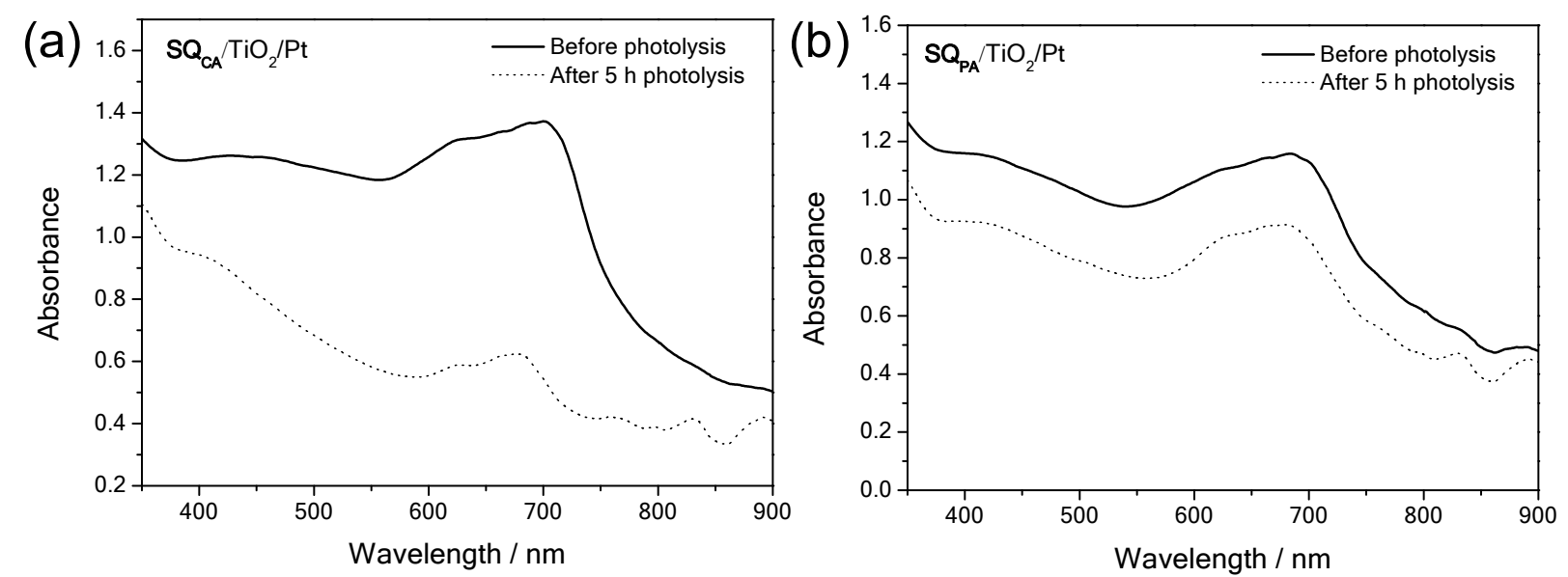

Figure S4. Diffuse-reflectance spectra (DRS) comparison of (a, left) $\mathbf{S Q}_{\mathbf{C A}} / \mathrm{TiO}_{2} / \mathrm{Pt}$ and (b, right) $\mathbf{S Q}_{\mathbf{P A}} / \mathrm{TiO}_{2} / \mathrm{Pt}$ powders after photoreaction $(0$ and $5 \mathrm{~h})$. 


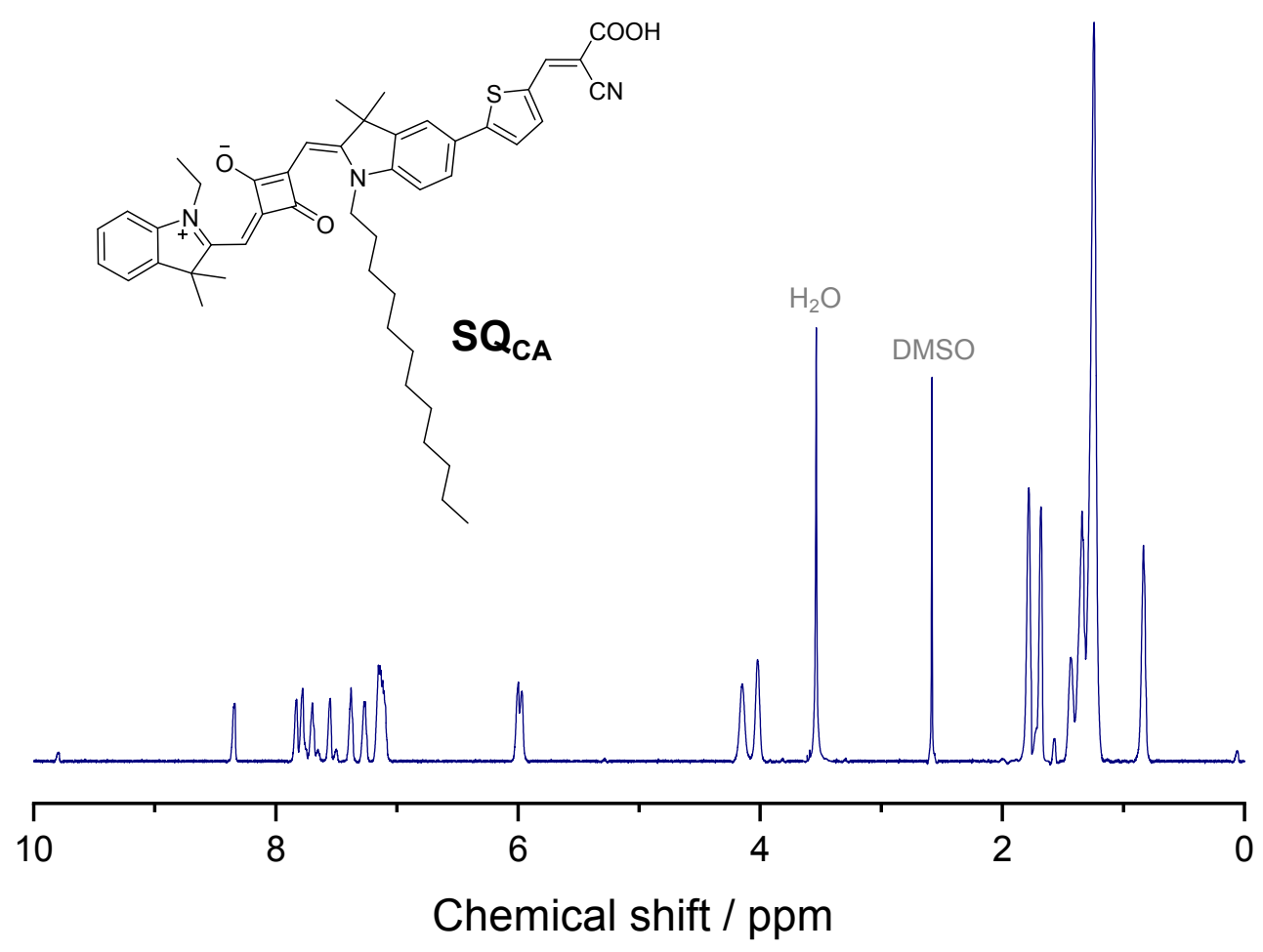

Figure S5. ${ }^{1} \mathrm{H}-\mathrm{NMR}$ spectroscopic view of $\mathbf{S Q}_{\mathbf{C A}}$. Inset describes the chemical structure of $\mathbf{S} \mathbf{Q}_{\mathbf{C A}}$. 


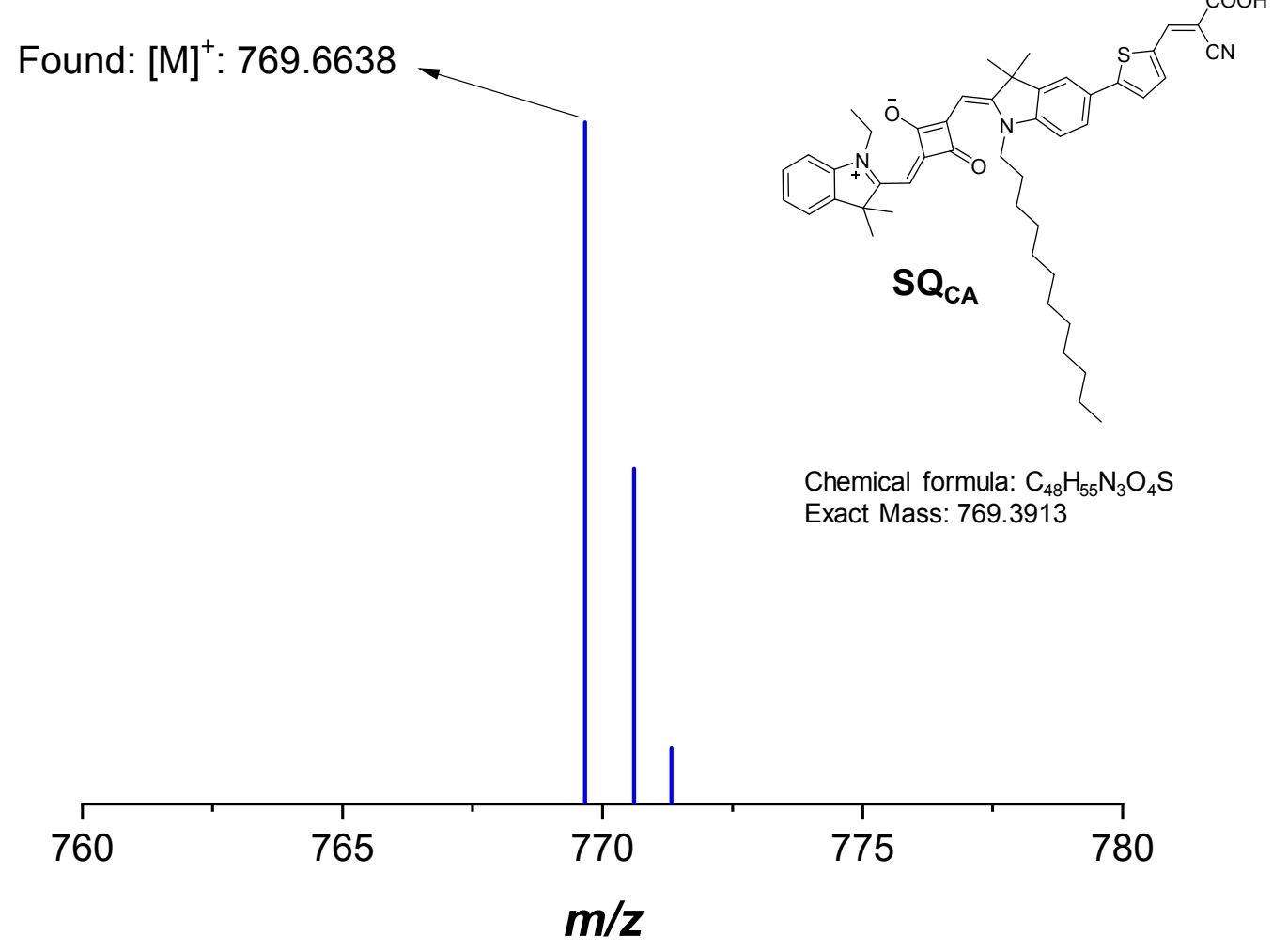

Figure S6. ESI-Mass spectra of $\mathbf{S Q}_{\mathbf{C A}}$. Inset describes the chemical structure and exact mass of $\mathbf{S Q}_{\mathrm{CA}}$. 


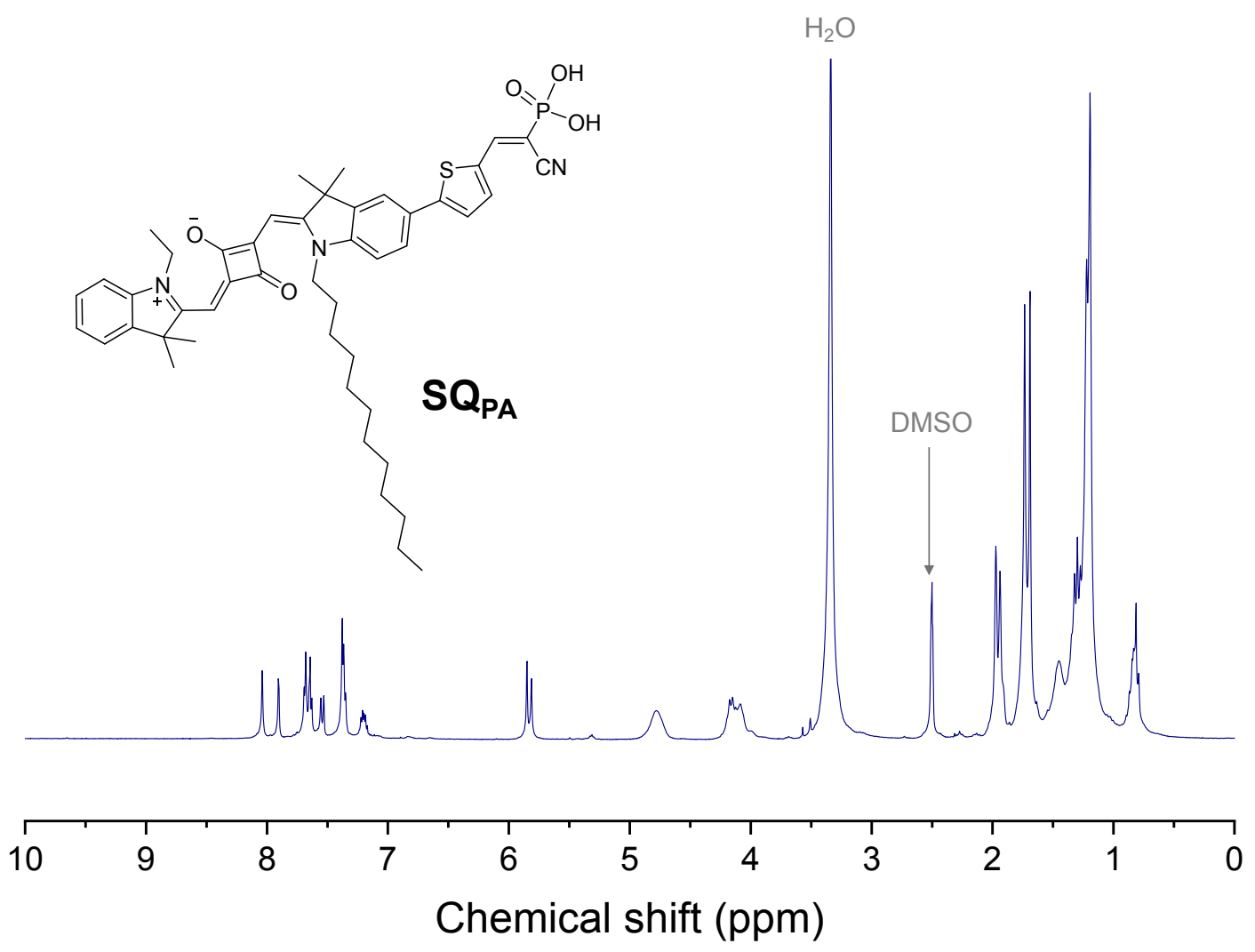

Figure S7. ${ }^{1} \mathrm{H}-\mathrm{NMR}$ spectroscopic view of $\mathbf{S Q}_{\mathbf{P A}}$. Inset describes the chemical structure of $\mathbf{S} \mathbf{Q}_{\mathbf{P A}}$. 


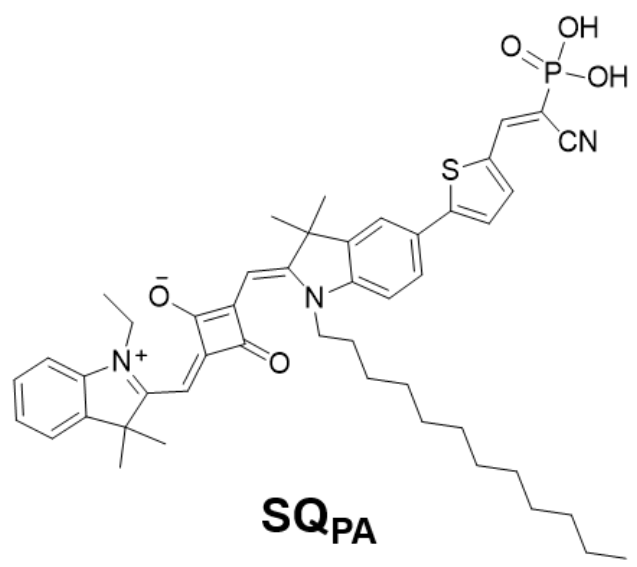

Chemical Formula: $\mathrm{C}_{47} \mathrm{H}_{56} \mathrm{~N}_{3} \mathrm{O}_{5} P S$

Exact Mass: 805.3678
$804.4196[\mathrm{M}-\mathrm{H}]^{-}$

805.4713

806.4747

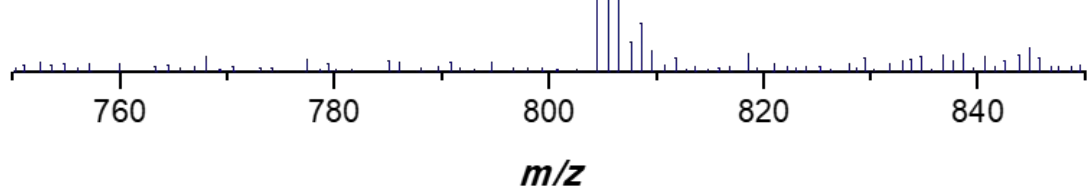

Figure S8. ESI-Mass spectra of SQPA. Inset describes the chemical structure and exact mass of SQPA. 


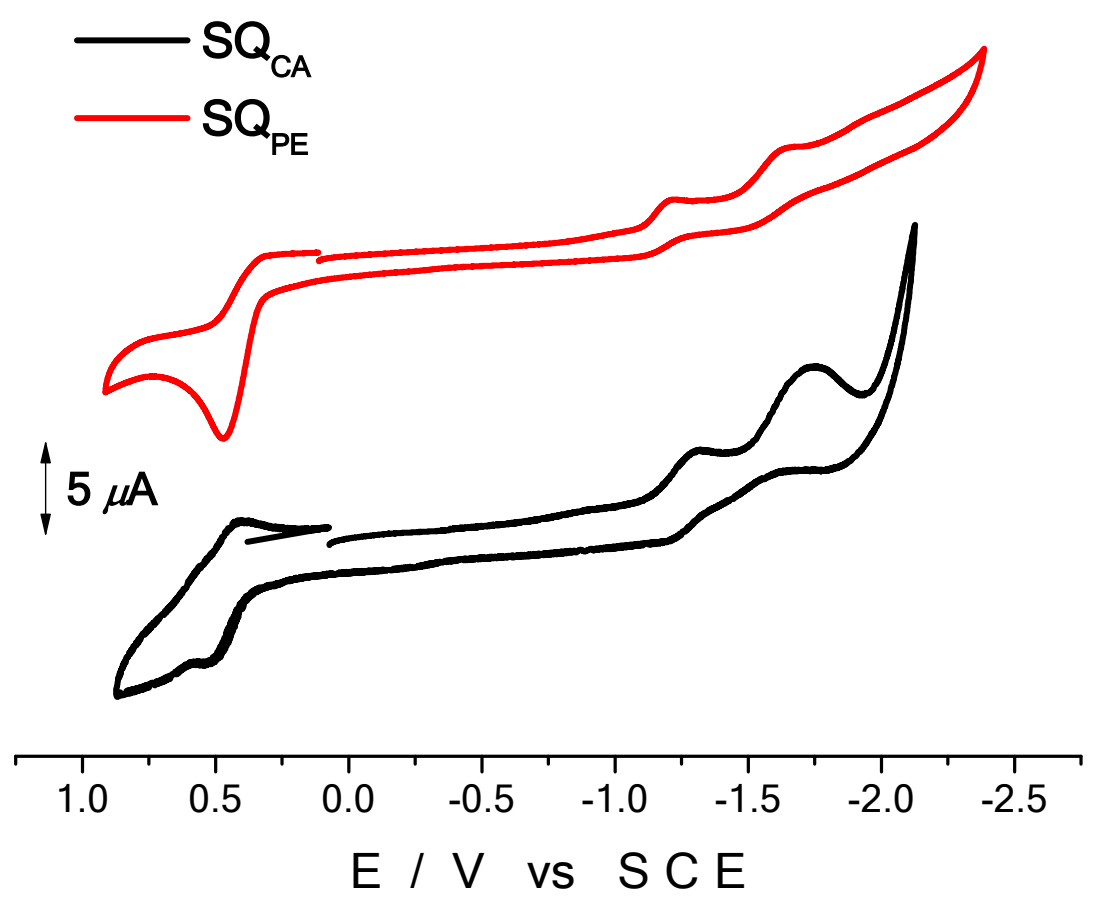

Figure S9. Cyclic voltammograms of the $\mathbf{S} \mathbf{Q}_{\mathbf{C A}}$ (black line) and $\mathbf{S} \mathbf{Q}_{\mathbf{P E}}$ (red line) measured in THF using $\left[n-\mathrm{Bu}_{4} \mathrm{~N}\right]^{+} \mathrm{PF}_{6}^{-}(0.1 \mathrm{M})$ as a supporting electrolyte. 

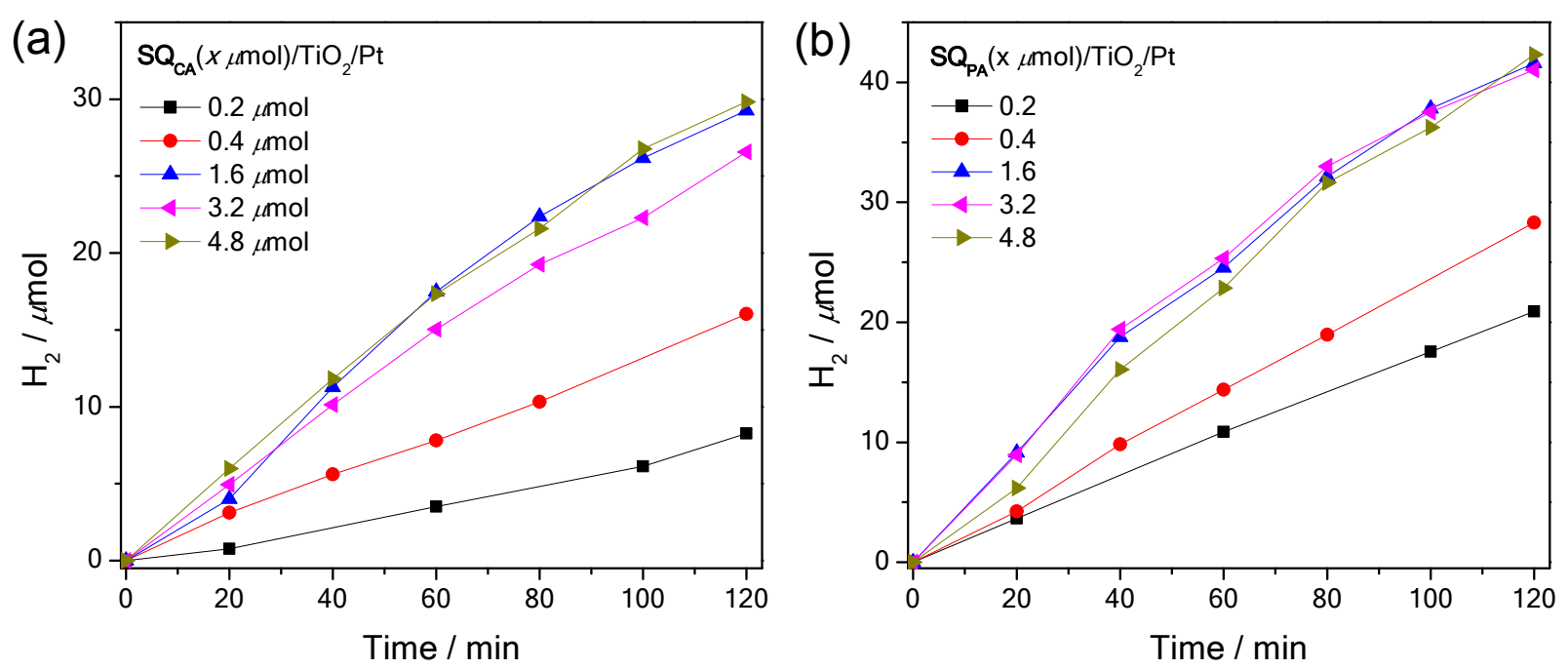

Figure S10. Plots of $\mathrm{H}_{2}$ formation $(\mu \mathrm{mol})$ versus time for $\mathbf{S Q s} / \mathrm{TiO}_{2} / \mathrm{Pt}$ with the variation of (a, left) $\mathbf{S Q}_{\mathbf{C A}}$ and (b, right) $\mathbf{S Q}_{\mathbf{P A}}$ loading amount from 0.2 to $4.8 \mu \mathrm{mol} ; 10 \mathrm{mg}$ of hybrids with platinized $\mathrm{TiO}_{2}$ particles in $3 \mathrm{~mL}$ of water in the presence of $0.1 \mathrm{M} \mathrm{AscH}(\mathrm{pH}=2.66)$; irradiation at $>500 \mathrm{~nm}$. 

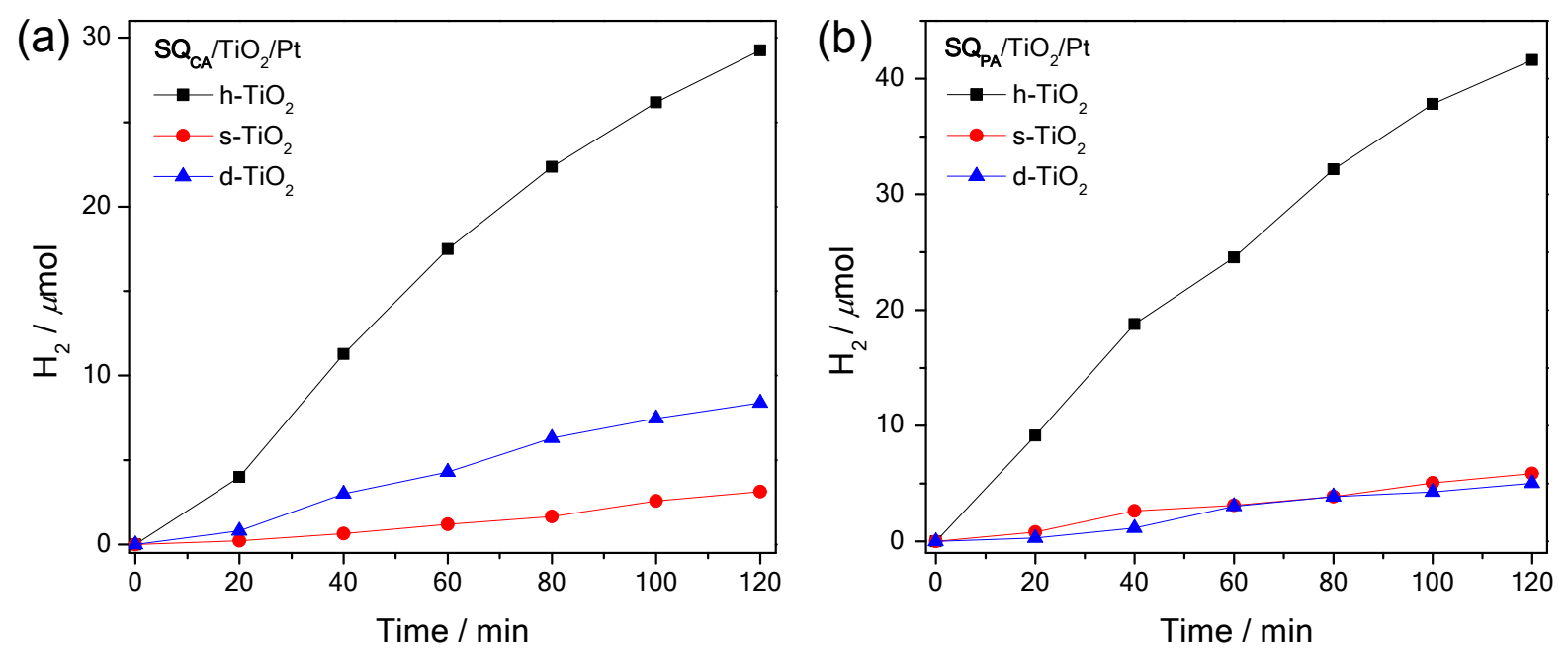

Figure S11. Time courses of $\mathrm{H}_{2}$ production by irradiation at $>500 \mathrm{~nm}$ for (a, left) $\mathbf{S} \mathbf{Q}_{\mathbf{C A}}(1.6$ $\mu \mathrm{mol}) / \mathrm{TiO}_{2} / \mathrm{Pt}$ and (b, right) $\mathbf{S} \mathbf{Q}_{\mathbf{P A}}(1.6 \mu \mathrm{mol}) / \mathrm{TiO}_{2} / \mathrm{Pt}\left(\mathrm{TiO}_{2}=\mathrm{h}-\mathrm{TiO}_{2}\right.$ (black square), s- $\mathrm{TiO}_{2}$ (red circle), and $\mathrm{d}-\mathrm{TiO}_{2}$ (blue triangle)); $10 \mathrm{mg}$ of hybrids with platinized $\mathrm{TiO}_{2}$ particles in $3 \mathrm{~mL}$ of water in the presence of $0.1 \mathrm{M} \mathrm{AscH}(\mathrm{pH}=2.66)$; irradiation at $>500 \mathrm{~nm}$. 


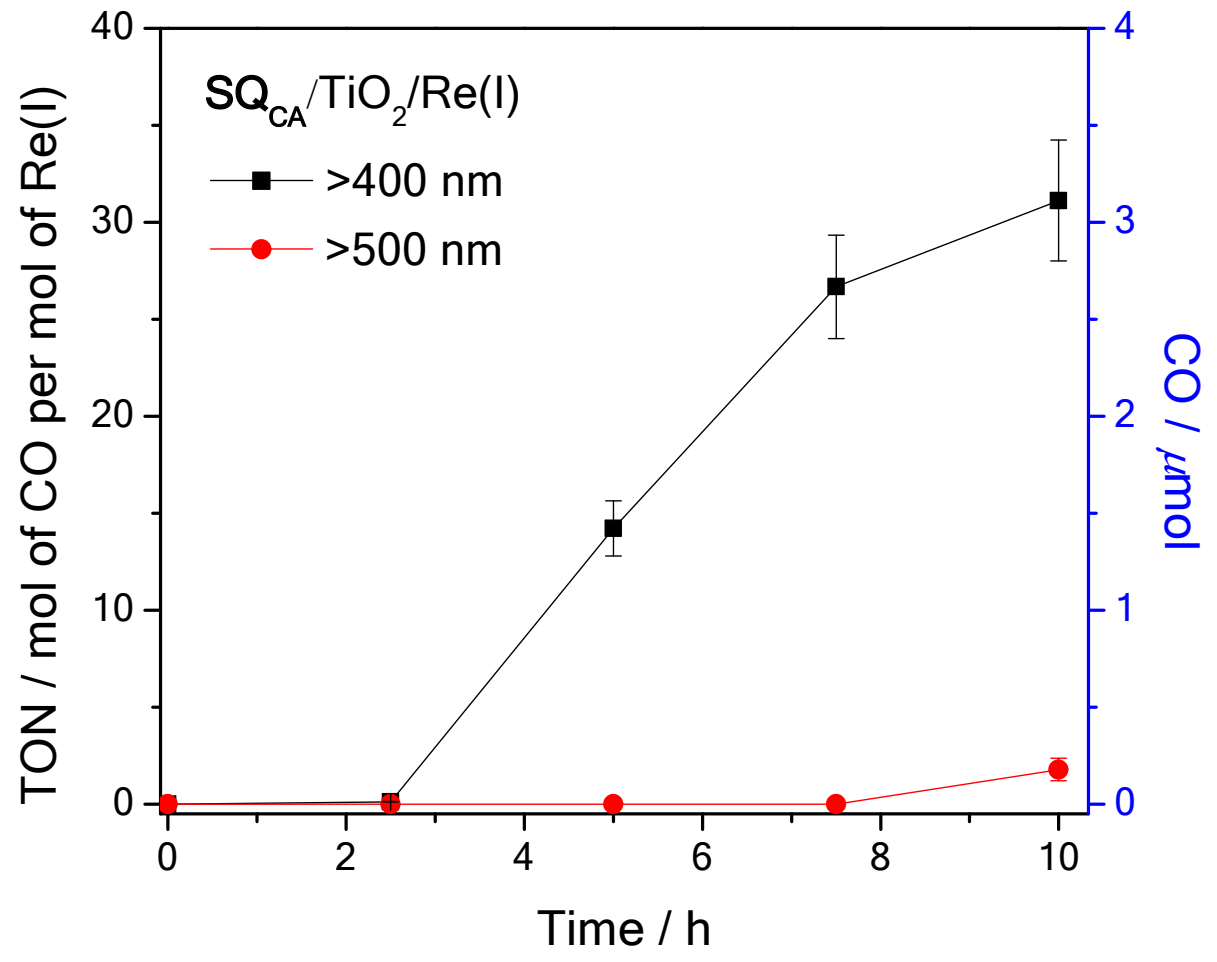

Figure S12. Plots of $\mathrm{CO}$ formation versus time for $\mathbf{S Q}_{\mathbf{C A}} / \mathrm{TiO}_{2} / \mathrm{Re}(\mathrm{I})$ under irradiation at $\lambda>400$ $\mathrm{nm}(-\mathbf{m}-)$ and at $\lambda>500 \mathrm{~nm}(-\bullet-)$. 
Theoretical calculation. All the calculations were performed on the platform of the Gaussian 09 package. ${ }^{1}$ The ground-state geometries were optimized by using the B3LYP density functional theory (DFT), ${ }^{2-5}$ 6-31G(d,p) basis set, ${ }^{6}$ and LANL2DZ basis set ${ }^{7}$ for zinc metal. Time-dependent DFT (TDDFT) calculations were then performed with the same functional and basis set to estimate the energies and oscillator strengths of the derivatives. The isodensity plots (contour $=0.03$ a.u.) of the frontier orbitals were visualized by the Chem3D Ultra program. 


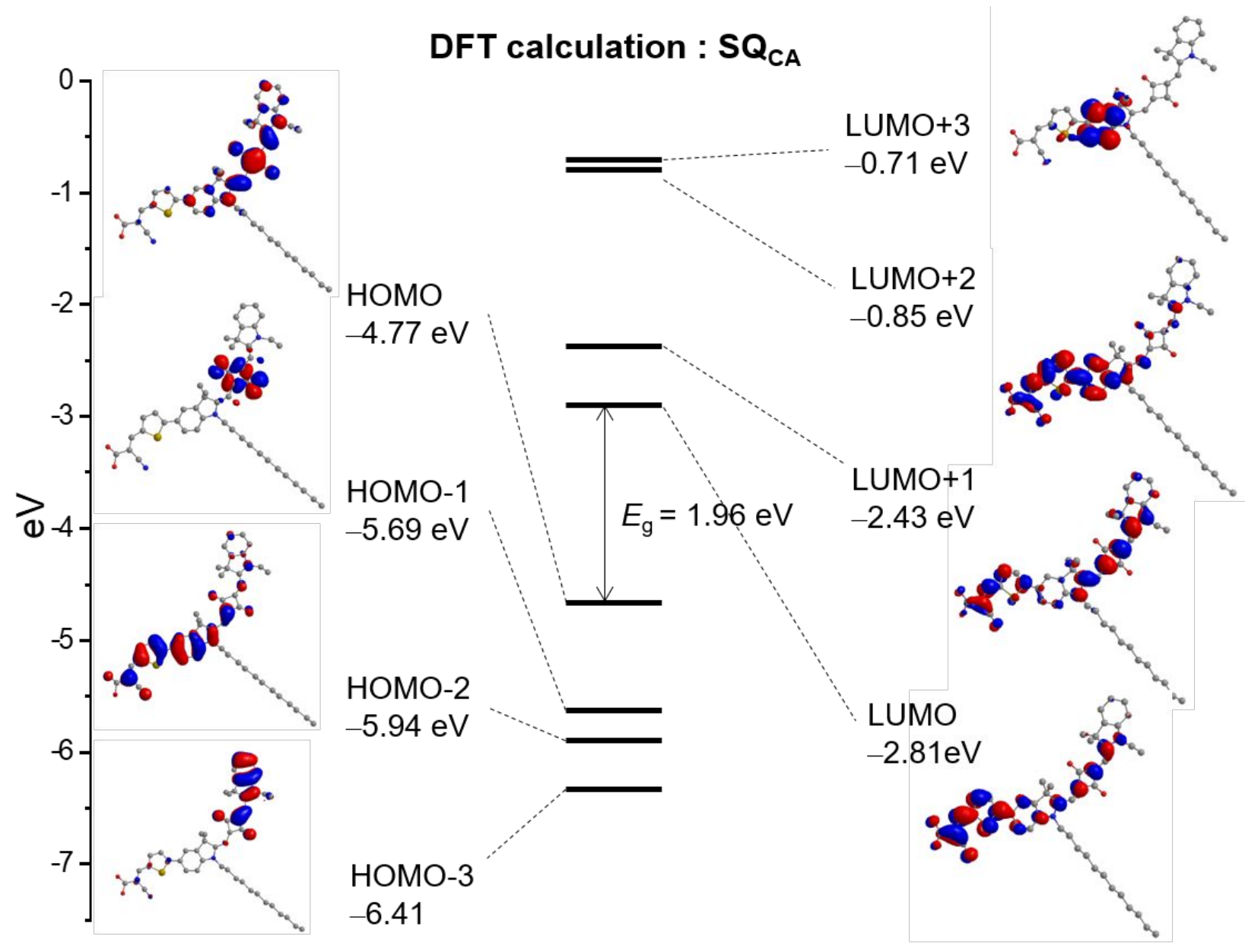

Figure S13. Spatial distributions for the frontier orbitals and calculated energy levels of $\mathbf{S} \mathbf{Q}_{\mathbf{C A}}$. 


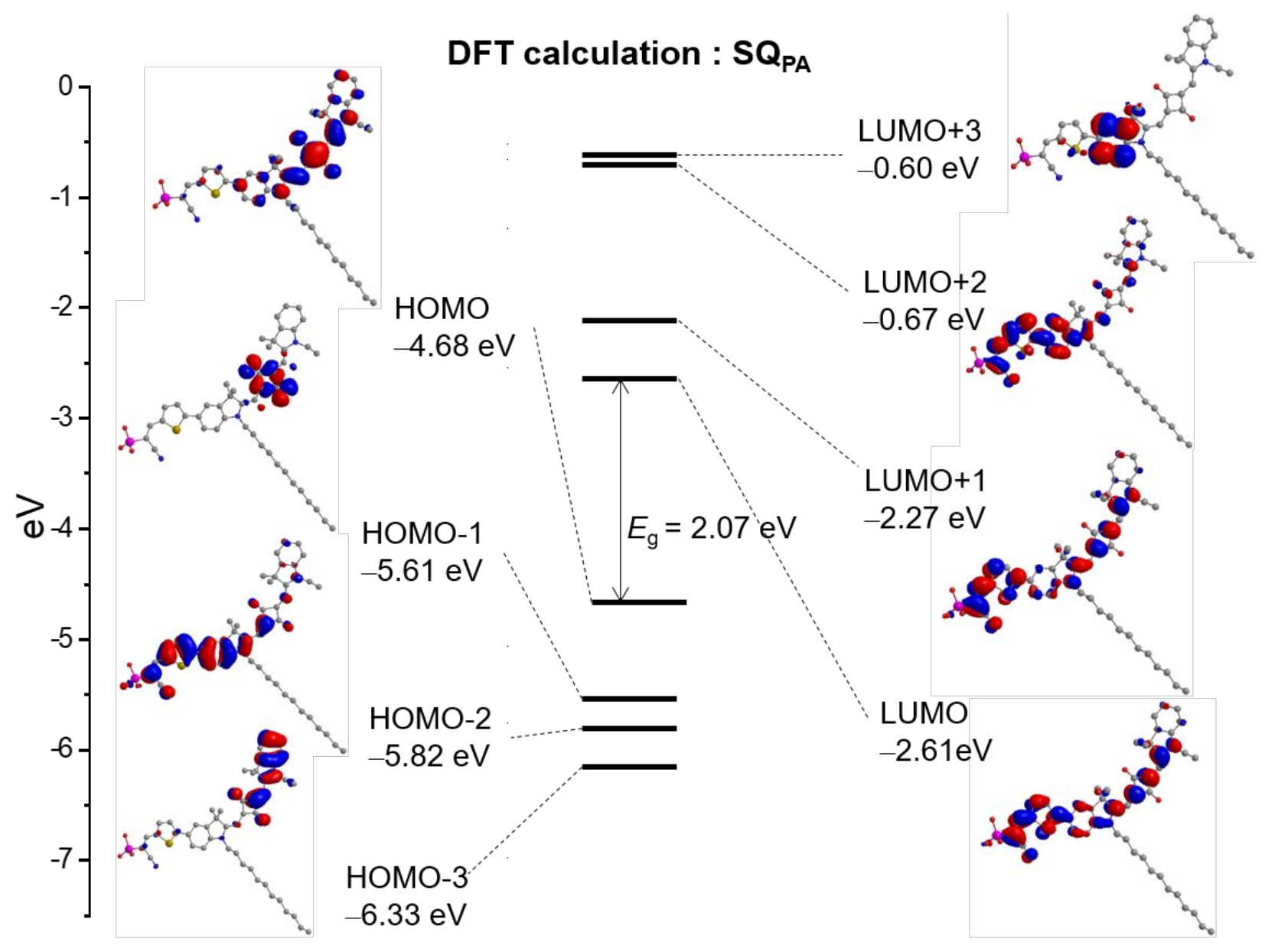

Figure S14. Spatial distributions for the frontier orbitals and calculated energy levels of $\mathbf{S Q}_{\mathbf{P A}}$. 


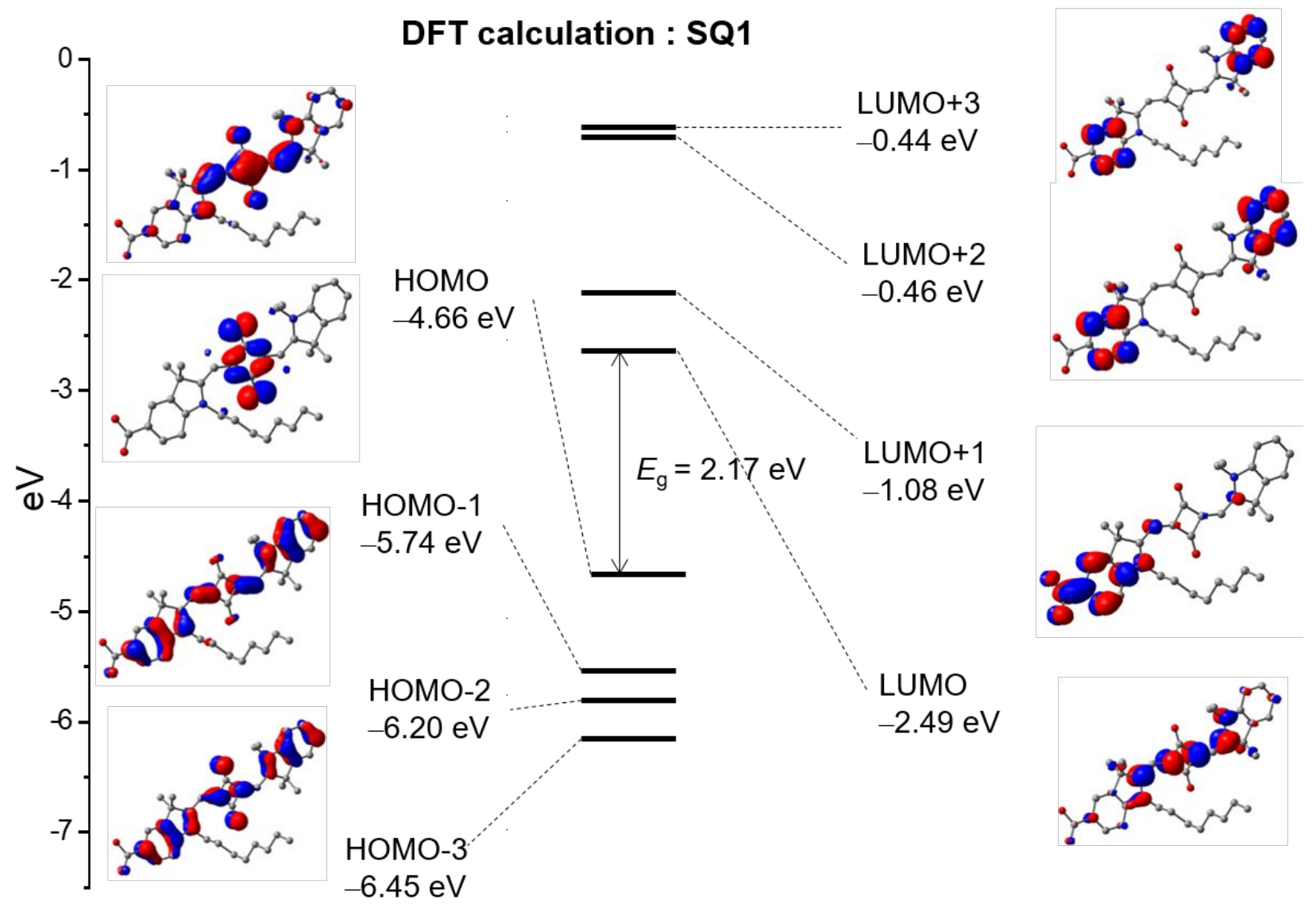

Figure S15. Spatial distributions for the frontier orbitals and calculated energy levels of SQ1. 
Table S1. Multi-exponential fitting results of time-resolved fluorescence signals.

\begin{tabular}{llllll}
\hline & dye & $\mathrm{A}_{1} / \%$ & $\tau_{1} / \mathrm{ps}$ & $\mathrm{A}_{2} / \%$ & $\tau_{2} / \mathrm{ns}$ \\
\hline \multirow{3}{*}{ Solution } & $\mathbf{S Q}_{\mathbf{C A}}$ & 64.6 & 140 & 35.4 & 0.51 \\
& $\mathbf{S Q}_{\mathbf{P A}}$ & 13.2 & 483 & 86.8 & 1.78 \\
\hline \multirow{2}{*}{ Film } & $\mathbf{S Q}_{\mathbf{C A}} / \mathrm{TiO}_{2}$ & 100 & 19.2 & & \\
& $\mathbf{S Q}_{\mathbf{P A}} / \mathrm{TiO}_{2}$ & 100 & 26.4 & & \\
& & & &
\end{tabular}




\section{References}

(1) Frisch, M. J.; Trucks, G. W.; Schlegel, H. B.; Scuseria, G. E.; Robb, M. A.; Cheeseman, J. R.; Scalmani, G.; Barone, V.; Mennucci, B.; Petersson, G. A.; Nakatsuji, H.; Caricato, M.; Li, X.; Hratchian, H. P.; Izmaylov, A. F.; Bloino, J.; Zheng, G.; Sonnenberg, J. L.; Hada, M.; Ehara, M.; Toyota, K.; Fukuda, R.; Hasegawa, J.; Ishida, M.; Nakajima, T.; Honda, Y.; Kitao, O.; Nakai, H.; Vreven, T.; Montgomery, Jr., J. A.; Peralta, J. E.; Ogliaro, F.; Bearpark, M.; Heyd, J. J.; Brothers, E.; Kudin, K. N.; Staroverov, V. N.; Kobayashi, R.; Normand, J.; Raghavachari, K.; Rendell, A.; Burant, J. C.; Iyengar, S. S.; Tomasi, J.; Cossi, M.; Rega, N.; Millam, J. M.; Klene, M.; Knox, J. E.; Cross, J. B.; Bakken, V.; Adamo, C.; Jaramillo, J.; Gomperts, R.; Stratmann, R. E.; Yazyev, O.; Austin, A. J.; Cammi, R.; Pomelli, C.; Ochterski, J. W.; Martin, R. L.; Morokuma, K.; Zakrzewski, V. G.; Voth, G. A.; Salvador, P.; Dannenberg, J. J.; Dapprich, S.; Daniels, A. D.; Farkas, Ö.; Foresman, J. B.; Ortiz, J. V.; Cioslowski, J.; Fox, D. J. Gaussian 09, Revision D.01; Gaussian Inc.: Wallingford, CT, 2009.

(2) Hohenberg, P.; Kohn, W. Inhomogeneous Electron Gas. Phys. Rev. 1964, 136, B864-B871.

(3) Kohn, W.; Sham, L. J. Self-Consistent Equations Including Exchange and Correlation Effects. Phys. Rev. 1965, 140, A1133-A1138.

(4) Parr, R. G.; Yang, W. Density-Functional Theory of Atoms and Molecules; Oxford University Press: New York, 1989.

(5) Petersson, G. A.; Bennett, A.; Tensfeldt, T. G.; Al-Laham, M. A.; Shirley, W. A.; Mantzaris, J. A Complete Basis Set Model Chemistry. I. The Total Energies of Closed-Shell Atoms and Hydrides of the First-Row Elements. J. Chem. Phys. 1988, 89, 2193-2218.

(6) Petersson, G. A.; Al-Laham, M. A. A Complete Basis Set Model Chemistry. II. Open-Shell Systems and the Total Energies of the First-Row Atoms. J. Chem. Phys. 1991, 94, 6081-6090.

(7) Hay, P. J.; Wadt, W. R. Ab Initio Effective Core Potentials for Molecular Calculations. Potentials for K to Au Including the Outermost Core Orbitals. J. Chem. Phys. 1985, 82, 299-310. 